\title{
Characterization of Gymnodinialimonas Ceratoperidinii gen. nov.,sp. nov., a New Bacterium Isolated From Rare Marine Dinoflagellate Ceratoperidinium Margalefii
}

\section{Yue Jiang}

KRIBB: Korea Research Institute of Bioscience and Biotechnology

\section{Yuxin Peng}

KRIBB: Korea Research Institute of Bioscience and Biotechnology

Hyeon Ho Shin

KIOST: Korea Institute of Ocean Science and Technology

Hyun Jung Kim

KRIBB: Korea Research Institute of Bioscience and Biotechnology

Ki-Hyun Kim

KRIBB: Korea Research Institute of Bioscience and Biotechnology

Lingmin Jiang

KRIBB: Korea Research Institute of Bioscience and Biotechnology

Jiyoung Lee

KRIBB: Korea Research Institute of Bioscience and Biotechnology

Zhun Li ( $\square$ lizhun@kribb.re.kr)

Korea Research Institute of Bioscience and Biotechnology https://orcid.org/0000-0001-8961-9966

\section{Research Article}

Keywords: Dinoflagellate, 16S rRNA gene, phylogeny, polyphasic taxonomy, whole-genome

Posted Date: December 1st, 2021

DOI: https://doi.org/10.21203/rs.3.rs-1126159/v1

License: (1) This work is licensed under a Creative Commons Attribution 4.0 International License. Read Full License 


\section{Abstract}

A bacterial strain, designated $\mathrm{J} 12 \mathrm{C} 1-\mathrm{MA}-4^{\top}$, was isolated from a liquid culture of dinoflagellate Ceratoperidinium margalefii. The bacterium was Gram-stain-negative, aerobic, and rod-shaped. Oxidase and catalase were positive. Optimal growth was observed at $30^{\circ} \mathrm{C}, \mathrm{pH} 7.0$, in the presence of $1 \%(\mathrm{w} / \mathrm{v}) \mathrm{NaCl}$. Phylogenetic analyses based on the 16S rRNA gene and 92 core genes sets indicated that the strain J12C1MA- $4^{\top}$ belongs to the family Rhodobacteraceae in the class Alphaproteobacteria and represented a separate taxon separated from other genera. 16S rRNA gene sequence of strain J12C1-MA-4 ${ }^{\top}$ showed high similarities to Loktanella ponticola KCTC $42133^{\top}$ (95.74\%), Pseudooctadecabacter jejudonensis KCTC $32525^{\top}$ (95.52\%) and Jannaschia helgolandensis KCTC $12191^{\top}$ (95.31\%) in the Rhodobacteraceae family. The genome length of strain J12C1-MA-4 ${ }^{\top}$ was 3621968 bp with a DNA G+C content of $64.48 \mathrm{~mol} \%$. The major cellular fatty acids of strain J12C1-MA-4 $4^{\top}$ were summed feature 8 (comprising $C_{18: 1} \omega 7 \mathrm{c}$ and/or $C_{18: 1} \omega 6 \mathrm{c}$ ) $(>10 \%$ ).

Phosphatidylglycerol (PG), phosphatidylcholine(PC), phospholipids (PL), lipids 1 (L1) and aminolipid (AL) were shown to be the major polar lipids. The sole predominant isoprenoid quinone is Q-10. Based on phylogenetic, phenotypic, chemotaxonomic and genomic features, strain $\mathrm{J} 12 \mathrm{C} 1-\mathrm{MA}-4^{\top}$ is considered to represent a new species in the new genus of the family Rhodobacteraceae for which the name Gymnodinialimonas ceratoperidinii gen. nov., sp. nov. is proposed. The type strain is $\mathrm{J} 12 \mathrm{C} 1-\mathrm{MA}-4^{\top}$ (=KCTC $82770^{\top}=$ GDMCC $\left.1.2729^{\top}\right)$.

\section{Introduction}

Dinoflagellates play a major role in the dynamics of the Earth's oceans and climate (Moustafa et al. 2010). Vitamins are an important growth factor for the majority of dinoflagellates (Tang et al. 2010). Marine Rhodobacteraceae are major vitamin suppliers for dinoflagellates (Sanudo-Wilhelmy et al. 2014). The family Rhodobacteraceae (Liang et al. 2021) belongs to the order Rhodobacterales within the class Alphaproteobacteria. Members are Gram-stain-negative, callus or rod-shaped and non-spore-forming bacteria. The major respiratory quinone is ubiquinone-10 (Q-10) and the major cellular fatty acid is unsaturated fatty acid $\mathrm{C}_{18: 1} \omega 7 \mathrm{c}$. And Rhodobacteraceae strains usually contain phosphatidylglycerol (PG), diphosphatidylglycerol (DPG), phosphatidylethanolamine (PE), and phosphatidylcholine (PC) as the main polar lipids. Members of the family Rhodobacteraceae are found in various saline environmental habitats, such as sea water, sea grass, marine sediment and hypersaline lake.

In the present study, we describe strain $\mathrm{J} 12 \mathrm{C} 1-\mathrm{MA}-4^{\top}$, which was isolated from rare dinoflagellate $C$. margalefii during a study on the relationship between bacteria and marine dinoflagellate. Polyphasic taxonomic analyses revealed that the strain $\mathrm{J} 12 \mathrm{C} 1-\mathrm{MA}-4^{\top}$ should be proposed as a novel species of a new genus in the family Rhodobacteraceae, named as Gymnodinialimonas ceratoperidinii gen. nov.,sp. nov.

\section{Materials And Methods}

\section{Isolation and culture conditions}


The bacterial strain was isolated from a liquid culture of the dinoflagellate Ceratoperidinium margalefii (J12C1), which was collected from the East China Sea (31॰59' 53" N, 127॰41' 59" E) (Figure 1). The dinoflagellate was isolated from seawater and the pure dinoflagellate was cultured in $\mathrm{F} / 2$ medium for 30 days. Collect 100 microliters from the seed culture sample and spread on MA agar (MA, Marine agar 2216) and then cultured at $25^{\circ} \mathrm{C}$. After 3 days, single colonies were transferred onto a new MA agar plate under the same conditions. A round, yellow, smooth, strain named J12C1-MA- $4^{\top}$ was stored at $-80^{\circ} \mathrm{C}$ in a suspension containing $10 \%(\mathrm{w} / \mathrm{v})$ skimmed milk, and was selected for polyphasic sorting, and incubated as usual with MA at $25^{\circ} \mathrm{C}$. Jannaschia helgolandensis KCTC $12191^{\top}$; Pseudooctadecabacter jejudonensis KCTC $32525^{\top}$; Loktanella acticola KCTC 52837'; Loktanella ponticola KCTC 42133' ; Alterinioella_nitratireducens KCTC $72738^{\top}$ were obtained from KCTC as closely related strains in order to further investigate the characteristics of strain J12C1-MA-4 ${ }^{\top}$.

\section{DNA extraction, PCR and 16S rRNA-based phylogenetic analysis}

Bacteria grown was used as a template on MA agar plates for 3 days. The DNA of strain F J12C1-MA-4 ${ }^{\top}$ was extracted with a spin columns filtration method (QIAamp DNA mini kit). The 16S rRNA gene of strain J12C1MA-4 ${ }^{\top}$ was amplified by polymerase chain reaction (PCR) using two bacterial specific universal primers $27 \mathrm{~F}$ and $1492 \mathrm{R}$ and then the purified PCR product was sequenced by Biofact using primers $518 \mathrm{~F}$ and $805 \mathrm{R}$. Sequences were viewed and assembled using Geneious Prime (https://www.geneious.com). The almost complete 16S rRNA gene sequence (1402 bp) was submitted to the GeneBank (https://www.ncbi.nlm.nih.gov/nuccore/MZ457320). Subsequently, the obtained 16S rRNA gene sequence was compared to the type strain sequences available on EzBioCloud server (http://www.ezbiocloud.net) (Yoon et al. 2017a). Phylogenetic analyses using the neighbor-joining, maximum-likelihood and maximumparsimony algorithms were performed as described by Jiang et al.(Jiang et al. 2021).

\section{Genome sequencing and analysis}

Whole-genome sequencing was performed based on the PacBio RSII (Pacific Biosciences Inc.) and the Illumina HiSeq 2500 sequencing platform (Macrogen, Korea). The sequence data were assembled using the RS HGAP (v3.0) De novo assembler. Genome annotation was performed using the NCBI Prokaryotic Genome Annotation Pipeline (PGAP) (Tatusova et al. 2016). Using the Genome-to-Genome Distance Calculator web server (http://ggdc.dsmz.de/distcalc2.php) and the ANI calculator (www.ezbiocloud.net/tools/ani) (Yoon et al. 2017b) to calculate Digital DNA-DNA hybridization (dDDH) values and average nucleotide identity (ANI)

values (J.P et al. 2013). AAl values between of complete genome of J12C1-MA-4 ${ }^{\top}$ and each reference genome were calculated using an online AAI calculation tool available at the webserver (http://enve-

omics.ce.gatech.edu/) (Luo et al. 2014). The up-to-date bacterial core genome (UBCG), consisting of 92 core genes, was used to construct a genome-wide phylogenetic tree after collecting the whole genome sequences of all closely related strains in NCBI GenBank as described by Na et al. (Na et al. 2018).

\section{Morphological, physiological and chemotaxonomic characterization}


Its morphological features were examined by using a scanning electron microscope (JEOL Ltd, Tokyo, Japan), samples were prepared as described by Li et al. (Li et al. 2019). To explore the optimal medium for J12C1-MA$4^{\top}$, a variety of media were selected here for testing, such as Marine agar 2216 (MA, Difco), Tryptic Soy agar (TSA, Difco), Luria-Bertani agar (LB, Difco), Potato Dextrose agar (PD, Difco), Nutrient agar (NA, beef extract $3.0 \mathrm{~g} / \mathrm{L}$, peptone $5.0 \mathrm{~g} / \mathrm{L}$, and agar $15.0 \mathrm{~g} / \mathrm{L}$ ). The temperature range for growth was determined in $\mathrm{MA}$ medium at $25^{\circ} \mathrm{C}$ for 3 days at different temperatures of $4,10,15,20,25,30,35,37,40,45,50$ and $60^{\circ} \mathrm{C}$. Growth at different pH values (pH 3.0-12.0 in 1.0 unit intervals) (adjusted with $1 \mathrm{~N} \mathrm{HCl}$ and $1 \mathrm{~N} \mathrm{NaOH}, 1.0 \mathrm{pH}$ unit interval) was measured in modified MA broth with $10 \mathrm{mM}$ acetate or $10 \mathrm{mM}$ Tris-HCl buffer described by Jiang et al. (Jiang et al. 2020). NaCl tolerance was tested in DW containing MA broth ( $\mathrm{NaCl}$ concentrations of $0-12 \%)$. The $\mathrm{pH}$ and $\mathrm{NaCl}$ tolerance were monitored by measuring the absorbance of OD600 using a DU 700 UV-Vis spectrophotometer (Beckman Coulter). Motility was assessed on soft agar (0.4\%; w/v) test tubes. Gram stain test using Gram stain kit (Difco). The bubbles produced after the addition of $3 \%(\mathrm{v} / \mathrm{v}$ ) hydrogen peroxide solution determined the activity of catalase, which was determined by the appearance of a purple color change in the colonies after the addition of an oxidase reagent (bioMérieux). Other biochemical characteristics were tested using API 20NE, API 50CH and API ZYM (bioMérieux) according to the manufacturer's instructions.

The appropriate liquid medium was prepared, and strain $\mathrm{J} 12 \mathrm{C} 1-\mathrm{MA}-4^{\top}$ and closely related strains were cultured in a shaker incubator, shaken for 3 days, and then the bacteria were harvested by centrifugation at $6000 \mathrm{rpm}$, lyophilized, and polar lipids and quinones were extracted with $100 \mathrm{mg}$ of lyophilized cells. For the analysis of chemosynthetic properties, methods including polar lipids (Minnikin et al. 1984) and quinones (Collins et al. 1980) were used. Polar lipid spots were separated by two-dimensional thin-layer chromatography and spray dyes including $0.2 \%$ ninhydrin (Sigma-Aldrich), $y$-naphthol, molybdenum blue (Sigma-Aldrich), 4\% phosphomolybdic acid and Dragendorff solution for the identification of aminocontaining lipids, glycolipids, phospholipids, total lipids and quaternary nitrogen-containing lipids, respectively. Cellular fatty acid methyl esters (FAMEs) were obtained from cells by saponification, methylation and extraction according to the protocol of Sherlock Microbial Identification System (MIDI, USA). Cellular FAMEs were separated by gas chromatography (6890) and identified and quantified using Sherlock Microbial Identification System software (Sasser 2006).

\section{Results And Discussion}

\section{Molecular characteristics}

Comparative analysis of $16 \mathrm{~S}$ rRNA (1402 bp) gene sequences revealed that strain J12C1-MA-4 ${ }^{\top}$ shows the highest similarity to L. ponticola KCTC $42133^{\top}$ (95.74\%), P. jejudonensis KCTC $32525^{\top}(95.52 \%), J$.

helgolandensis KCTC $12191^{\top}$ (95.31\%), and A. nitratireducens KCTC $72738^{\top}$ (93.9\%), L. acticola KCTC $52837^{\top}$ $(93.3 \%)$.

Phylogenetic analyses using the neighbor-joining, maximum-likelihood and maximum-parsimony algorithms were performed as described by Jiang et al. (Jiang et al. 2021). NJ, ML, and ME algorithms obtained similar results (Figure 2). Based on $16 \mathrm{~S}$ rRNA phylogenetic analysis, strain $\mathrm{J} 12 \mathrm{C} 1-\mathrm{MA}-4^{\top}$ is located on a separate 
branch in the family Rhodobacteraceae, next to the genus Loktanella, Planktomarina, Thalassobius, Pseudooctadecabacter and Octadecabacter.

The whole-genome length of strain J12C1-MA-4 ${ }^{\top}$ was $3621968 \mathrm{bp}$. Using the whole-genome calculated the GC-content was $64.48 \%$. After annotation with PGAP (GenBank accession number: CP079194), there were 3428 protein-coding genes, 42 transfer RNA genes, 3 ncRNA and 6 ribosomal RNA genes, including $25 \mathrm{~S}$ ribosomal RNA genes, $216 \mathrm{~S}$ rRNA genes, $223 \mathrm{~S}$ rRNA genes. The 3406 genes were functionally classified according to clusters of orthologous groups (COG) assignments, and $31.5 \%$ of the total assigned COGs were classified in the unknown group, followed by the amino acid transport and metabolism (9.6\%), energy production and conversion (5.9\%), transcription (5.3\%). The digital DDH values, ANI value and AAI of strain J12C1-MA-4 ${ }^{\top}$ to close related strain J. helgolandensis KCTC $12191^{\top}$; P. jejudonensis KCTC $32525^{\top}$; L. acticola KCTC $52837^{\top}$; L. ponticola KCTC $42133^{\top}$; A. nitratireducens KCTC $72738^{\top}$ revealed $18.8 \%, 20.9 \%,-19.3 \%$, $18.7 \%$, and $71.59 \%, 70.69 \%,-69.58 \%, 73.54$ and $60.55 \%, 61.28 \%,-, 60.18 \%, 64.99 \%$ are shown in Table 2 respectively. The $\mathrm{dDDH}$ values were much lower than the threshold for proposing novel bacterial species (dDDH: $70 \%$ ) (Chun et al. 2018).ANI values for J12C1-MA-4 ${ }^{\top}$ are below the identified genus score threshold compared to closely related species (ANI: 92-94\%) (Palmer et al. 2020). In addition, the AAl values between J12C1-MA-4 ${ }^{\top}$ and other closely related genomes in the Rhodobacteraceae family ranged from $60-65 \%$, which is below the defined genus delimitation threshold. (AAl: 80\%) (Luo et al. 2014). The phylogenomic tree showed that strain $\mathrm{J} 12 \mathrm{C} 1-\mathrm{MA}-4^{\mathrm{T}}$ is also located on a separate branch in the family Rhodobacteraceae. Nonetheless, strain J12C1-MA-4 ${ }^{\top}$ had a far phylogenetic distance to all type strains within Rhodobacteraceae (Fig. 2), suggesting that strain $\mathrm{J} 12 \mathrm{C} 1-\mathrm{MA}-4^{\top}$ was quite different Rhodobacteraceae from all other type strains. Therefore, the results of the phylogenetic analyses suggest that $\mathrm{J} 12 \mathrm{C} 1-\mathrm{MA}-4^{\top}$ can be classified as a novel genus and species in the family of Rhodobacteraceae. Additionally, genes related to the metabolism, including complete pathway about carbohydrate (glycolysis, gluconeogenesis, Pyruvate oxidation, TCA cycle, first carbon oxidation, PRPP biosynthesis, D-galactonate degradation), lipid (fatty acid biosynthesis, acyl-CoA synthesis, Phosphatidylcholine (PC) biosynthesis), were encoded in the genome. Metabolism of cofactors and vitamins (Coenzyme A biosynthesis, Lipoic acid biosynthesis, Molybdenum cofactor biosynthesis, Cobalamin biosynthesis) were found to be encoded in the genome.

\section{Morphological, physiological and chemotaxonomic characteristics}

Colonies grown on MA medium were yellow-colored, circular, smooth, and $1 \mathrm{~mm}$ in diameter after 3 days of incubation. Strain $\mathrm{J} 12 \mathrm{C} 1-\mathrm{MA}-4^{\top}$ can be grown in the temperature ranges $4-37^{\circ} \mathrm{C}$ (optimum $30^{\circ} \mathrm{C}$ ), salt concentration range 0-8\% (optimum 1\%), pH range 5-8 (optimum 7), and this strain is Gram-negative, aerobic, non-motile, catalase-positive, and oxidase-positive. Cells were rod-shaped in shape, $0.2-0.5 \mu \mathrm{m}$ width, and 1.0-1.8 $\mu \mathrm{m}$ length (Figure 4). Additional characteristics of strain $\mathrm{J} 12 \mathrm{C} 1-\mathrm{MA}-4^{\top}$ with closely related strains are shown in Tables 1 and 3.

The polar lipid profile of strain J12C1-MA-4 ${ }^{\top}$ was dominated by phosphatidylglycerol (PG), phosphatidylcholine(PC), phospholipids (PL), lipids 1 (L1) and aminolipid (AL) (Figure S1), J12C1-MA-4 ${ }^{\top}$ and reference strain both have phosphatidylglycerol (PG) and phosphatidylcholine(PC). The predominant 
isoprenoid quinone of strain J12C1-MA-4 ${ }^{\top}$ was Q-10, which was consistent with other members of the family Rhodobacteraceae. Strain J12C1-MA-4 $4^{\top}$ contained Summed feature 8 (comprising $\mathrm{C}_{18: 1} \omega 7 \mathrm{c}$ and/or $\mathrm{C}_{18: 1} \omega 6 \mathrm{c}$ ) $(79.14 \%)$ as the major fatty acids (>10\%) (Table 4). Regarding fatty acid composition, strain J12C1-MA-4 ${ }^{\top}$ had only Summed feature 8 (including $\mathrm{C} 18: 1 \omega 7 \mathrm{c}$ and/or $\mathrm{C} 18: 1 \omega 6 \mathrm{c}$ ) with more than $10 \%$, and the percentage was as high as $79.14 \%$, the most abundant fatty acids in the reference strains were all summed feature 8 , but for its reference strains, more than one component over 10\%, for example, J. helgolandensis KCTC $12191^{\top}$ had summed feature 8 (40.66\%), $\mathrm{C}_{18: 0}(12.73 \%)$ and $\mathrm{C}_{19: 0}$ cyclo $\omega 8 \mathrm{c}(27.90 \%)$ as major components (>10\%), Pseudooctadecabacter jejudonensis KCTC $32525^{T}$ had $\mathrm{C}_{18: 1} \omega 7 \mathrm{c} 11$-methyl (10.72\%), summed feature 8 $(71.37 \%)$ as major components (>10\%), Loktanella acticola KCTC $52837^{T}$ is mainly composed of, $\mathrm{C}_{18: 1} \omega 7 \mathrm{c}$ 11-methyl (11.24\%), summed feature 8 (69.85\%). These results indicate that strain J12C1-MA-4 ${ }^{\top}$ was affiliated with the family Rhodobacteraceae, suggesting that strain $\mathrm{J} 12 \mathrm{C} 1-\mathrm{MA}-4^{\top}$ is distinguished from the closely related strains.

\section{Taxonomic conclusion}

In summary, the phylogenetic and chemotaxonomic analysis suggest that strain $\mathrm{J} 12 \mathrm{C} 1-\mathrm{MA}-4^{\top}$ belongs to the family Rhodobacteraceae. However, 16S rRNA similarity (below 96.9\%), ANI, AAl, fatty acid composition, dDDH values as well as some physiological characteristics (such as API 20NE, API 50CH, and API ZYM test), show that strain $\mathrm{J} 12 \mathrm{C} 1-\mathrm{MA}-4^{\top}$ was different with the closely related strains. Thus, strain $\mathrm{J} 12 \mathrm{C} 1-\mathrm{MA}-4^{\top}$ represents a new species in the new genus of the family Rhodobacteraceae, and the name of Gymnodinialimonas ceratoperidinii gen. nov., sp. nov. is proposed.

Description of Gymnodinialimonas gen. nov.

Gymnodinialimonas(Gym.no.di.ni.a.li.mo'nas. N.L. pl. neut. n. Gymnodiniales, unarmored dinoflagellates; L. fem. n. monas, unit, cell; N.L. fem. n. Gymnodinialimonas, a monad isolated from unarmored dinoflagellates)

Cells are Gram-strain-negative, aerobic, oxidase and catalase were positive. Predominant respiratory quinone is Q-10. The predominant fatty acids are summed feature 8 (comprising $\mathrm{C}_{18: 1} \omega 7 \mathrm{c}$ and/or $\mathrm{C}_{18: 1} \omega 6 \mathrm{c}$ ). The principal polar lipids were phosphatidylglycerol (PG), phosphatidylcholine(PC), phospholipids (PL), lipids 1 (L1) and aminolipid (AL). The type species of Gymnodinialimonas is Gymnodinialimonas centrodinii.

Description of Gymnodinialimonas ceratoperidinii sp. nov.

Gymnodinialimonas ceratoperidinii (ce.ra.to.pe.ri.di'ni.i. N.L. gen. n. ceratoperidrii of the dinoflagellate Ceratoperidinium margalefii, the source of the isolation)

Colonies were circular, yellow-colored, smooth, and $1 \mathrm{~mm}$ in diameter when cultured on MA medium at $25^{\circ} \mathrm{C}$ for 3 days. Strain can grow at $\mathrm{MA}$, the temperature ranged from at $4-37^{\circ} \mathrm{C}$ (optimum $30^{\circ} \mathrm{C}$ ), at $\mathrm{pH} 5-8.0$ (optimum $\mathrm{pH} 7.0$ ), and in the presence of $0-8 \% \mathrm{NaCl}$ (optimum 1\%). Cells were aerobic, Gram-negative, rodshaped (1.0-1.8 X 0.2-0.5 $\mu \mathrm{m})$, non-motile, catalase-positive, and oxidase-positive. API 20NE tests indicated positive reactions for urease. API $50 \mathrm{CH}$ test showed the production of acid from esculin ferric citrate. In the API ZYM kit, show the positive result of acid phosphatase, valine arylamidase, cystine arylamidase, naphthol- 
as-bi-phosphohydrolase, alkaline phosphatase. The principal polar lipids of strain J12C1-MA-4 ${ }^{\top}$ were phosphatidylglycerol (PG), phosphatidylcholine(PC), phospholipids (PL), lipids 1 (L1) and aminolipid (AL). Q10 is the predominant isoprenoid quinone. The principal fatty acids of strain $\mathrm{J} 12 \mathrm{C} 1-\mathrm{MA}-4^{\top}$ were summed feature 8 (comprising $\mathrm{C} 18: 1 \omega 7 \mathrm{c}$ and/or C18:1w6c).

The type strain is J12C1-MA-4 ${ }^{\top}\left(=\right.$ KCTC $82770^{\top}=$ GDMCC $\left.1.2729^{\top}\right)$, which has been isolated from the dinoflagellate Ceratoperidinium margalefii.

The GenBank accession numbers for the 16S rRNA gene and the whole-genome sequence of strain J12C1MA-4 ${ }^{\top}$ are MZ457320 and CP079194, respectively.

\section{Declarations}

\section{Data availability}

The GenBank accession numbers of the 16S rRNA gene and the whole-genome sequences of the strain J12C1-MA-4 ${ }^{\top}$ are MZ457320 and CP079194, respectively. This strain can be obtained from the Korea Collection for Type Cultures (KCTC 82770 $)$ and the Guangdong Microbial Culture Collection Center (GDMCC $\left.1.2729^{\top}\right)$.

\section{Funding}

This work was supported by grant from the Korea Research Institute of Bioscience and Biotechnology (KRIBB) Research Initiative Program and by the National Research Foundation of Korea (NRF) grant funded by the Korea government (MSIT) (No. 2021R1C1C1008377).

\section{Conflict of interest}

The authors declare that there are no conflicts of interest.

\section{References}

1. Chun $\mathrm{J}$ et al (2018) Proposed minimal standards for the use of genome data for the taxonomy of prokaryotes. Int J Syst Evol Microbiol 68:461-466. doi: 10.1099/ijsem.0.002516

2. Collins M, Shah H, Minnikin D (1980) A note on the separation of natural mixtures of bacterial menaquinones using reverse phase thin-layer chromatography. J Appl Bacteriol 48:277-282

3. J.P M-K, Auch AF, Klenk HP, Goker M (2013) Genome sequence-based species delimitation with confidence intervals and improved distance functions. BMC Bioinformatics 186:1471-2105

4. Jiang $L$ et al (2020) Saccharibacillus brassicae sp. nov., an endophytic bacterium isolated from kimchi cabbage (Brassica rapa subsp. pekinensis) seeds. J Microbiol 58:24-29. doi: 10.1007/s12275-020-93466

5. Jiang $Y$ et al (2021) Flagellatimonas centrodinii gen. nov., sp. nov., a novel member of the family Nevskiaceae isolated from toxin-producing dinoflagellate Centrodinium punctatum. Int J Syst Evol Microbiol 71. doi: $10.1099 /$ ijsem.0.005084 
6. Li Z et al (2019) Discovery of a New Clade Nested Within the Genus Alexandrium (Dinophyceae): Morphomolecular Characterization of Centrodinium punctatum. F J R Taylor Protist 170:168-186. doi:

10.1016/j.protis.2019.02.003. Cleve

7. Liang KYH, Orata FD, Boucher YF, Case RJ (2021) Roseobacters in a Sea of Poly- and Paraphyly: Whole Genome-Based Taxonomy of the Family Rhodobacteraceae and the Proposal for the Split of the "Roseobacter Clade" Into a Novel Family, Roseobacteraceae fam. nov. Front Microbiol 12:683109. doi: 10.3389/fmicb.2021.683109

8. Luo C, Rodriguez RL, Konstantinidis KT (2014) MyTaxa: an advanced taxonomic classifier for genomic and metagenomic sequences. Nucleic Acids Res 42:e73. doi: 10.1093/nar/gku169

9. Minnikin D et al (1984) An integrated procedure for the extraction of bacterial isoprenoid quinones and polar lipids. J Microbiol Methods 2:233-241

10. Moustafa A et al (2010) Transcriptome profiling of a toxic dinoflagellate reveals a gene-rich protist and a potential impact on gene expression due to bacterial presence. PLoS ONE 5:e9688. doi: 10.1371/journal.pone.0009688

11. Na SI, Kim YO, Yoon SH, Ha SM, Baek I, Chun J (2018) UBCG: Up-to-date bacterial core gene set and pipeline for phylogenomic tree reconstruction. J Microbiol 56:280-285. doi: 10.1007/s12275-018-8014-6

12. Palmer M, Steenkamp ET, Blom J, Hedlund BP, Venter SN (2020) All ANIs are not created equal: implications for prokaryotic species boundaries and integration of ANIs into polyphasic taxonomy. Int J Syst Evol Microbiol 70:2937-2948. doi: 10.1099/ijsem.0.004124

13. Sanudo-Wilhelmy SA, Gomez-Consarnau L, Suffridge C, Webb EA (2014) The role of B vitamins in marine biogeochemistry. Ann Rev Mar Sci 6:339-367. doi: 10.1146/annurev-marine-120710-100912

14. Sasser M (2006) Bacterial identification by gas chromatographic analysis of fatty acids methyl esters (GC-FAME). MIDI Technical MIDI Technical Note \#101 MIDI Inc, Newark, DE, USA

15. Tang YZ, Koch F, Gobler CJ (2010) Most harmful algal bloom species are vitamin B1 and B12 auxotrophs. Proc Natl Acad Sci U S A 107:20756-20761. doi: 10.1073/pnas.1009566107

16. Tatusova T et al (2016) NCBI prokaryotic genome annotation pipeline. Nucleic Acids Res 44:6614-6624. doi: 10.1093/nar/gkw569

17. Yoon SH et al (2017a) Introducing EzBioCloud: a taxonomically united database of 16S rRNA gene sequences and whole-genome assemblies. Int J Syst Evol Microbiol 67:1613-1617. doi: 10.1099/ijsem.0.001755

18. Yoon SH, Ha SM, Lim J, Kwon S, Chun J (2017b) A large-scale evaluation of algorithms to calculate average nucleotide identity. Antonie Van Leeuwenhoek 110:1281-1286. doi: 10.1007/s10482-017-0844-4

\section{Tables}

Table 1. Comparison of the physiological and biochemical differences between strain J12C1-MA-4T and phylogenetically related type strains in the family Rhodobacteraceae based on 16S rRNA gene and genome sequences. 
1, Gymnodinialimonas ceratoperidinii J12C1-MA-4 ${ }^{\mathrm{T}}$; 2, Jannaschia helgolandensis KCTC $12191^{\mathrm{T}}$;

3, Pseudooctadecabacter jejudonensis KCTC 32525'; 4, Loktanella acticola KCTC 52837'; 5, Loktanella ponticola KCTC $42133^{\mathrm{T}}$; 6, Alterinioella nitratireducens KCTC $72738^{\mathrm{T}}$; ND, not determined.

\begin{tabular}{|c|c|c|c|c|c|c|}
\hline Characteristics & 1 & $2^{\mathrm{a}}$ & $3^{b}$ & $4^{c}$ & $5^{d}$ & $6^{e}$ \\
\hline $\begin{array}{l}\text { Isolation } \\
\text { source }\end{array}$ & $\begin{array}{l}\text { Ceratoperidinium } \\
\text { margalefii }\end{array}$ & $\begin{array}{l}\text { North } \\
\text { Sea } \\
\text { water }\end{array}$ & $\begin{array}{l}\text { Zone } \\
\text { where the } \\
\text { ocean and } \\
\text { a } \\
\text { freshwater } \\
\text { spring } \\
\text { meet }\end{array}$ & Seawater & Seawater & Seawater \\
\hline $\begin{array}{l}\text { Colony } \\
\text { morphology }\end{array}$ & $\begin{array}{l}\text { Circular, yellow, } \\
\text { smooth }\end{array}$ & $\begin{array}{l}\text { small, } \\
\text { whitish, } \\
\text { shiny }\end{array}$ & $\begin{array}{l}\text { circular, } \\
\text { slightly } \\
\text { convex, } \\
\text { smooth, } \\
\text { glistening, } \\
\text { reddish } \\
\text { orange }\end{array}$ & $\begin{array}{l}\text { circular, } \\
\text { slightly } \\
\text { convex, } \\
\text { glistening, } \\
\text { smooth, } \\
\text { greyish } \\
\text { yellow }\end{array}$ & $\begin{array}{l}\text { circular, } \\
\text { slightly } \\
\text { convex, } \\
\text { smooth, } \\
\text { glistening, } \\
\text { greyish- } \\
\text { yellow }\end{array}$ & $\begin{array}{l}\text { circular, } \\
\text { convex, } \\
\text { smooth, and } \\
\text { nontransparent }\end{array}$ \\
\hline
\end{tabular}

Growth

condition

\begin{tabular}{|c|c|c|c|c|c|c|}
\hline $\begin{array}{l}\text { temperature } \\
\text { range }\left({ }^{\circ} \mathrm{C}\right) \\
\text { (optimum) }\end{array}$ & $4-37$ (30) & $\begin{array}{l}15-30 \\
(25- \\
30)\end{array}$ & $\begin{array}{l}15-35 \\
(30)\end{array}$ & $4-30(25)$ & $4-30(25)$ & $10-37(30)$ \\
\hline Motile & Non-motile & $\begin{array}{l}\text { Non- } \\
\text { motile }\end{array}$ & $\begin{array}{l}\text { Non- } \\
\text { motile }\end{array}$ & $\begin{array}{l}\text { Non- } \\
\text { motile }\end{array}$ & $\begin{array}{l}\text { Non- } \\
\text { motile }\end{array}$ & Non-motile \\
\hline Cell size $(\mu \mathrm{m})$ & $\begin{array}{l}1.0-1.8 X \\
0.2-0.5\end{array}$ & $\begin{array}{l}1.9- \\
3.2 x \\
0.7- \\
1.1\end{array}$ & $\begin{array}{l}0.2-0.5 x \\
0.8-5.0\end{array}$ & $\begin{array}{l}0.4-1.2 \times \\
>0.4\end{array}$ & $\begin{array}{l}0.2-0.7 x \\
0.4-7.0\end{array}$ & $\begin{array}{l}0.8-1.2 \times 1.0- \\
2.5\end{array}$ \\
\hline $\begin{array}{l}\text { pH range } \\
\text { (optimum) }\end{array}$ & $5.0-9.0(7.0)$ & $\begin{array}{l}7.0- \\
8.0 \\
(N D)\end{array}$ & $\begin{array}{l}6.0-8.0 \\
(7.0-8.0)\end{array}$ & $\begin{array}{l}6.0- \\
8.0(7.0- \\
8.0)\end{array}$ & $\begin{array}{l}5.5- \\
8.0(7.0- \\
8.0)\end{array}$ & $6.5-9.5(8.0)$ \\
\hline $\begin{array}{l}\mathrm{NaCl} \\
\text { concentration } \\
\text { range (\%) } \\
\text { (optimum) }\end{array}$ & $0-8(1)$ & $\begin{array}{l}1-7 \\
(N D)\end{array}$ & $1-6(2)$ & $\begin{array}{l}0-8.0 \\
(2.0-3.0)\end{array}$ & $\begin{array}{l}0.5-6.0 \\
(2)\end{array}$ & $1.0-11(3.0)$ \\
\hline
\end{tabular}

a Data from Wagner et al. (Wagner-Dobler et al. 2003); ${ }^{\text {b }}$ Data from Billerbeck et al. (Billerbeck et al. 2015) ; ${ }^{c}$ Data from Park et al. (Park et al. 2017); d Data from Jung et al. (Jung et al. 2014); e Data from Kong et al. (Kong et al. 2021).

\section{Table 2. Comparison of the genome features differences between strain $\mathrm{J} 12 \mathrm{C} 1-\mathrm{MA}-4^{\top}$ and phylogenetically related type strains in the family Rhodobacteraceae based on 16S rRNA gene and genome sequences.}

1, Gymnodinialimonas ceratoperidinii J12C1-MA-4 ${ }^{\top} ; 2$, Jannaschia helgolandensis KCTC $12191^{\top}$; 3, Pseudooctadecabacter jejudonensis KCTC $32525^{\top}$; 4, Loktanella acticola KCTC 52837; 
5, Loktanella ponticola KCTC $42133^{\top} ;$; 6 , Alterinioella_nitratireducens KCTC $72738^{\top}$; ND, not determined.

\begin{tabular}{lllllll} 
& 1 & $2^{\mathrm{a}}$ & $3^{\mathrm{b}}$ & $4^{\mathrm{c}}$ & $5^{\mathrm{d}}$ & $6^{\mathrm{e}}$ \\
\hline ANI & - & $71.59 \%$ & $70.69 \%$ & - & $69.58 \%$ & $73.54 \%$ \\
\hline AAl & - & $60.55 \%$ & $61.28 \%$ & - & $60.18 \%$ & $64.99 \%$ \\
\hline dDDH & - & $18.8 \%$ & $20.9 \%$ & - & $19.3 \%$ & $18.7 \%$ \\
\hline G+C & $64.48 \mathrm{~mol} \%$ & - & - & $57.3 \mathrm{~mol} \%$ & $55.9 \mathrm{~mol} \%$ & $65.4 \mathrm{~mol} \%$
\end{tabular}

${ }^{a}$ Data from Wagner et al. (Wagner-Dobler et al. 2003); ${ }^{b}$ Data from Billerbeck et al. (Billerbeck et al. 2015) $;{ }^{c}$

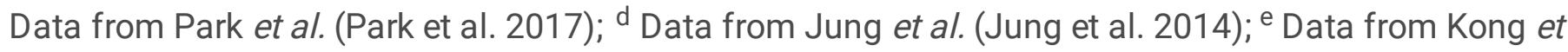
al. (Kong et al. 2021).

Table 3. Biochemical differences between strain J12C1-MA-4 ${ }^{\top}$ phylogenetically related type starins in the family Rhodobacteraceae based on 16S rRNA gene and genome sequences.

1, Gymnodinialimonas ceratoperidinii J12C1-MA-4 ${ }^{\top} ; 2$, Jannaschia helgolandensis KCTC 12191';

3, Pseudooctadecabacter jejudonensis KCTC $32525^{\top}$; 4, Loktanella acticola KCTC 52837'; 5, Loktanella ponticola KCTC $42133^{\top} ; 6$, Alterinioella_nitratireducens KCTC $72738^{\top}$; All data were obtained from parallel experiments in this study under certain defined conditions. +, positive; -, negative; w, weak.

Table 4. Cellular fatty acid compositions (>1\%) of the strain $\mathrm{J} 12 \mathrm{C} 1-\mathrm{MA}-4^{\top}$ and phylogenetically related type strains in the family Rhodobacteraceae based on 16S rRNA gene and genome sequences.

1, Gymnodinialimonas ceratoperidinii J12C1-MA-4 ${ }^{\top} ; 2$, Jannaschia helgolandensis KCTC $12191^{\top}$

3, Pseudooctadecabacter jejudonensis KCTC $32525^{\top}$; 4, Loktanella acticola KCTC 52837'; 5, Loktanella ponticola KCTC $42133^{\top} ; 6$, Alterinioella_nitratireducens KCTC $72738^{\top}$; All data are from the present study. Values are presented as the percentages of total fatty acids. ND, not detected. Major components $(>10 \%)$ are shown in bold. 
Characteristics

$\begin{array}{llllll}1 & 2 & 3 & 4 & 5 & 6\end{array}$

\section{API 20NE}

Indoleproduction (TRyptoPhane)

Arginine DiHydrolase

UREase

\section{Acid production (API 50CH)}

Glycerol

L-arabinose

W W - - - -

L-xylose

D-fructose

D-mannose

D-mannitol

Arbutin

Esculin ferric citrate

$+\quad+\quad+\quad+\quad+\quad+$

D-turanose

D-fucose

L-fucose

Potassium 5-KetoGluconate

\section{ZYM}

Alkaline phosphatase

Esterase(C8)

Leucine arylamidase

Valine arylamidase

Cystine arylamidase

W W

$-\quad W$

W W - - - -

Acid phosphatase

Naphthol-AS-BI-phosphohydrolase

a-Galactosidase

$\beta$-Galactosidase

a-glucosidase

$\beta$-glucosidase 
$\begin{array}{llllllll}\text { Fatty acids } & 1 & 2 & 3 & 4 & 5 & 6\end{array}$

Saturated

\begin{tabular}{lllllll}
\hline $\mathrm{C}_{16: 0}$ & 4.11 & 0.69 & 3.73 & 7.71 & 4.79 & 19.94 \\
\hline $\mathrm{C}_{18: 0}$ & 1.2 & 12.73 & 3.86 & 1.69 & 0.36 & 1.29
\end{tabular}

\section{Hydroxy}

\begin{tabular}{lllllll}
\hline $\mathrm{C}_{10: 0} 30 \mathrm{H}$ & 1.98 & 2.95 & 1.77 & 1.63 & 0.99 & 2.14 \\
\hline $\mathrm{C}_{12: 0} 30 \mathrm{H}$ & $\mathrm{ND}$ & $\mathrm{ND}$ & $\mathrm{ND}$ & $\mathrm{ND}$ & $\mathrm{ND}$ & 4.31 \\
\hline $\mathrm{C}_{12: 1} 30 \mathrm{H}$ & $\mathrm{ND}$ & $\mathrm{ND}$ & 4.51 & 3.27 & 3.16 & $\mathrm{ND}$ \\
\hline $\mathrm{C}_{16: 0} 2 \mathrm{HH}$ & 3.52 & $\mathrm{ND}$ & $\mathrm{ND}$ & $\mathrm{ND}$ & $\mathrm{ND}$ & 3.07 \\
\hline $\mathrm{C}_{18: 1} 2 \mathrm{OH}$ & 3.69 & $\mathrm{ND}$ & $\mathrm{ND}$ & $\mathrm{ND}$ & $\mathrm{ND}$ & $\mathrm{ND}$ \\
\hline
\end{tabular}

Unsaturated

$\begin{array}{lllllll}\mathrm{C}_{20: 2} \omega 6,9 \mathrm{c} & \mathrm{ND} & 1.53 & \mathrm{ND} & \mathrm{ND} & \mathrm{ND} & 0.88 \\ \mathrm{C}_{18: 1} \omega 7 \mathrm{c} 11 \text {-methyl } & 3.83 & 7.05 & 10.72 & 11.24 & 2.42 & 1.24 \\ \mathrm{C}_{19: 0} \text { cyclo } \omega 8 \mathrm{c} & \mathrm{ND} & 27.90 & \mathrm{ND} & 0.33 & \mathrm{ND} & 31.58\end{array}$

Summed feature*

\begin{tabular}{lllllll}
\hline 2 & 0.17 & 1.58 & ND & ND & ND & ND \\
\hline 3 & 1.05 & 0.38 & 1.17 & 1.53 & 13.56 & 1.47 \\
\hline 7 & ND & 1.76 & 1.74 & 0.75 & 0.33 & ND \\
\hline 8 & 79.14 & 40.66 & 71.37 & 69.85 & 73.61 & 32.17
\end{tabular}

*There are two or three fatty acids divided into a group which cannot be separated by GLC with the MIDI System, stipulated as summed features. Summed feature 2 contains $C_{12: 0}$ aldehyde, unknown 10.928; Summed feature 3 contains $\mathrm{C}_{16: 1} \omega 7 \mathrm{c}$ and/or $\mathrm{C}_{16: 1} \omega 6 \mathrm{c}, \mathrm{C}_{16: 1} \omega 6 \mathrm{c}$ and/or $\mathrm{C}_{16: 1} \omega 7 \mathrm{c}$; Summed feature 7 contains $\mathrm{C} 19: 1 \omega 6$ cand/or $\mathrm{C} 19: 1 \omega 7$ cand/or cyclo $\mathrm{C} 19: 0$. Summed feature 8 contains $\mathrm{C}_{18: 1} \omega 7 \mathrm{c}$ and/or $\mathrm{C}_{18: 1} \omega 6 \mathrm{c}$.

\section{Figures}




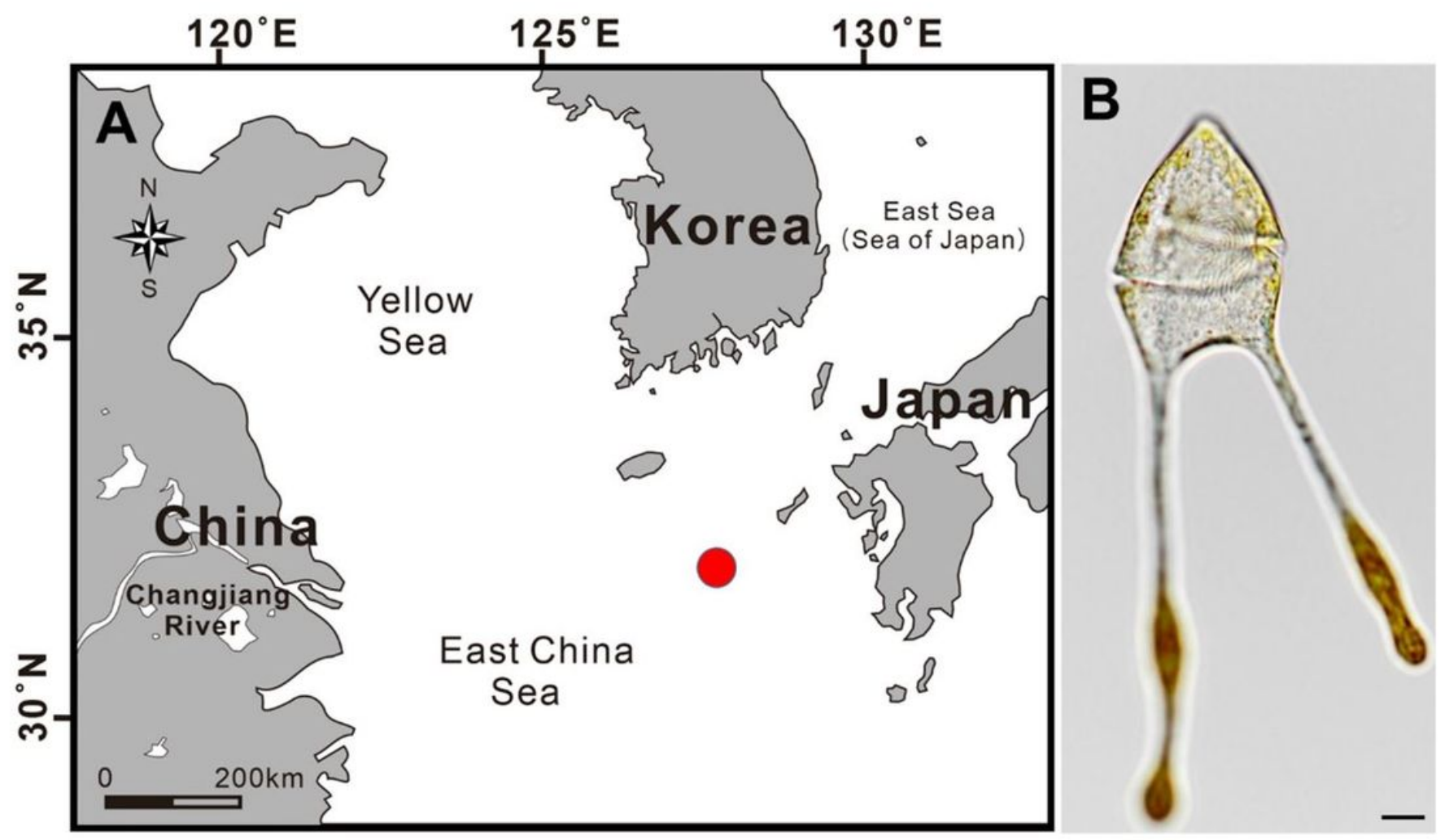

Figure 1

(A) Location of sampling site in East China Sea; (B) Light micrograph of vegetative cell of Ceratoperidinium margalefii (J12C1). Scale bar $=10 \mu \mathrm{m}$. 


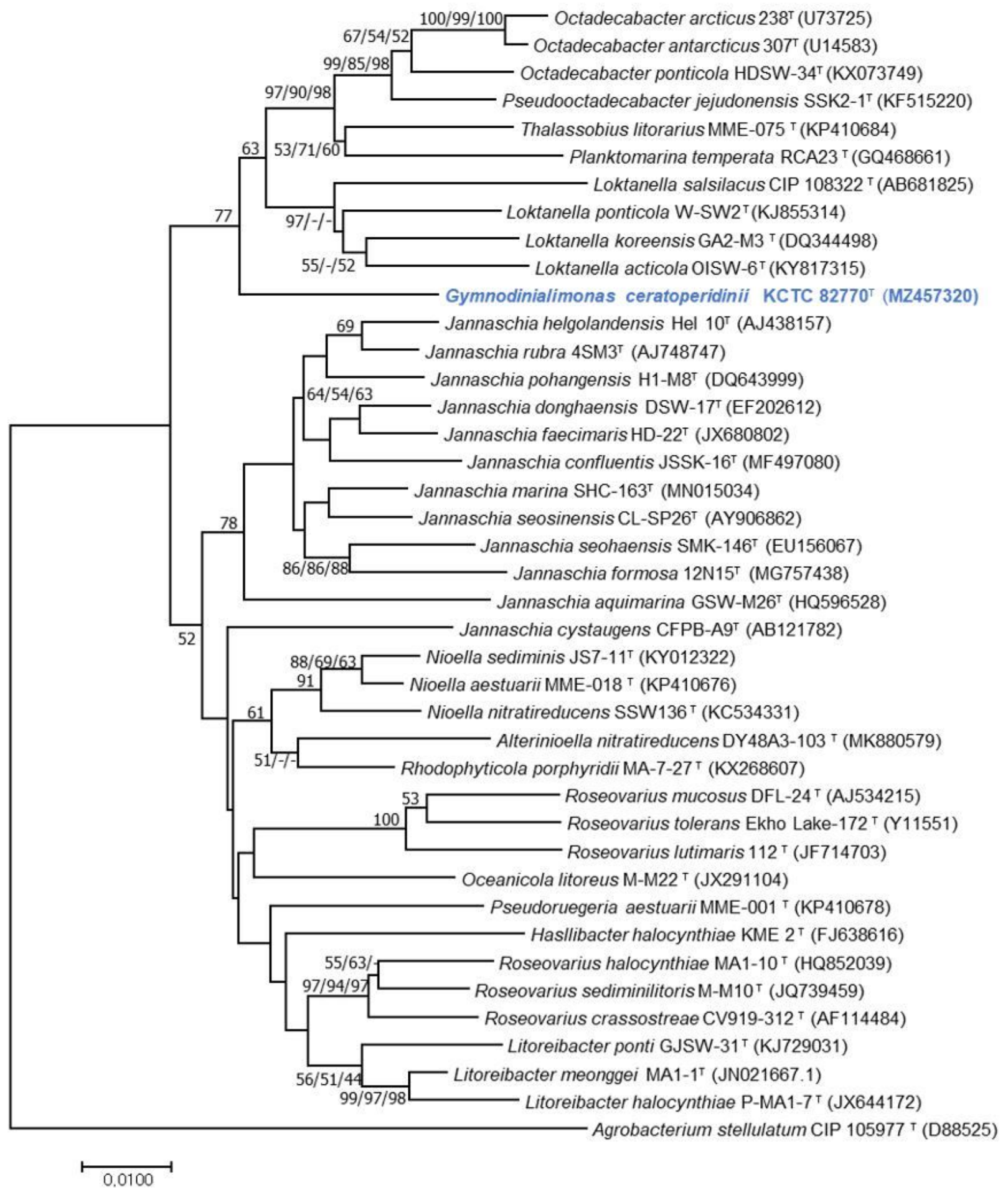

\section{Figure 2}

Neighbor-joining (NJ) phylogenetic tree based on 16S rRNA gene sequences showing the position of Gymnodinialimonas ceratoperidinii J12C1-MA-4T(=KCTC 82770T) and closely related taxa within the family Rhodobacteraceae. Bootstrap values of $>50 \%$ based on 1000 replications are shown at branch nodes. The filled circles on the nodes indicate that the relationship is also restored by the maximum likelihood $(\mathrm{ML})$ or minimum evolution (ME) algorithms, while the open circles indicate the nodes restored by the ML and ME algorithms. Strain numbers and GenBank accession numbers follow taxon names. Scale bar $=0.01$ nucleotide substitutions per site. 


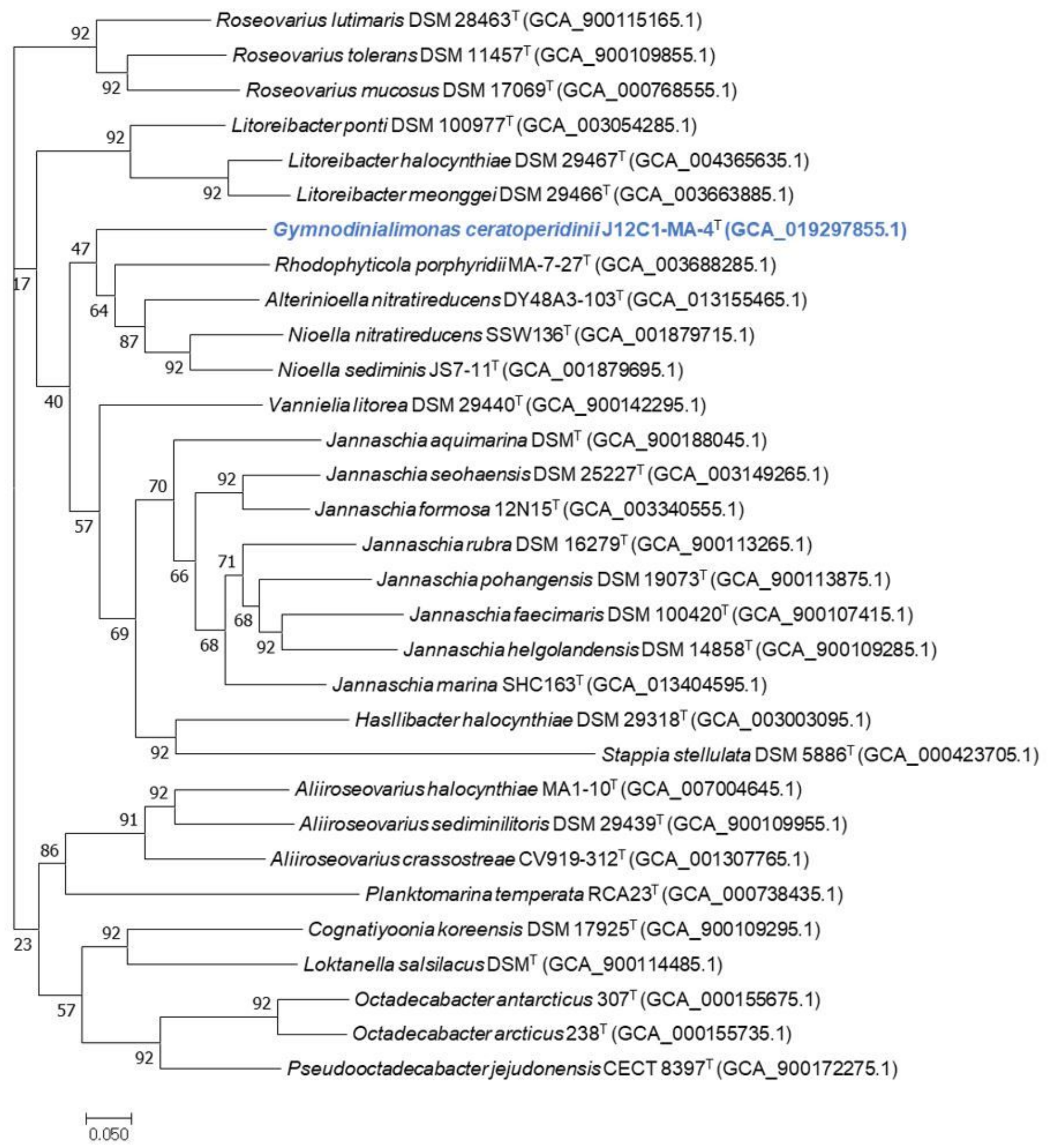

Figure 3

Maximum likelihood phylogenetic tree showing relationship between strain J12C1-MA-4T(=KCTC 82770T) and the most closely related type strains based on UBCGs (concatenated alignment of bacterial 92 core genes: alaS, argS, aspS, cgtA, coaE, cysS, dnaA, dnaG, dnaX, engA, ffh, fmt, frr, ftsY, gmk, hisS, ileS, infB, infC, ksgA, lepA, leuS, ligA, nusA, nusG, pgk, pheS, pheT, prfA, pyrG, recA, rbfA, rnc, rplA, rplB, rplC, rpID, rplE, rplF, rpll, rplJ, rpIK, rpIL, rpIM, rpIN, rpIO, rpIP, rpIQ, rpIR, rpIS, rpIT, rplU, rpIV, rpIW, rpIX, rpmA, rpmC, rpml, rpoA, rpoB, rpoC, rpsB, rpsC, rpsD, rpsE, rpsF, rpsG, rpsH, rpsl, rpsJ, rpsK, rpsL, rpsM, rpsO, rpsP, rpsQ, rpsR, rpsS, rpsT, secA, secG, secY, serS, smpB, tig, tilS, truB, tsaD, tsf, uvrB, ybeY and ychF). Gene support index (GSI, left) and bootstrap 
values (right) are indicated at the nodes. Strain numbers and GenBank accession numbers follow taxon names. Scale bar $=0.05$ nucleotide substitutions per site.

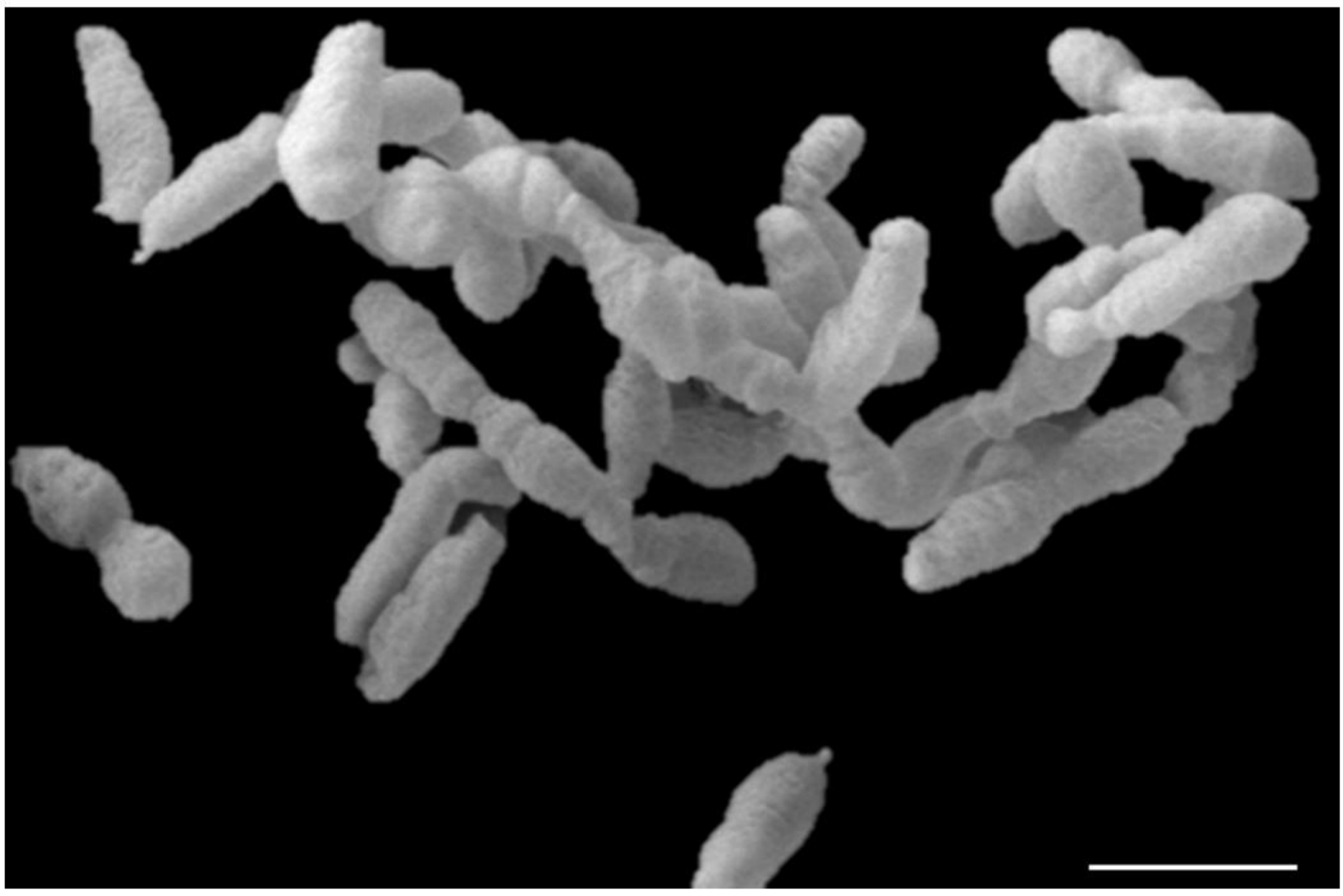

\section{Figure 4}

Scanning electron microscopy micrograph of the strain J12C1-MA-4T. Scale bar $=1 \mu \mathrm{m}$.

\section{Supplementary Files}

This is a list of supplementary files associated with this preprint. Click to download.

- J12C1MA4supplementarymaterial.docx 